\section{Conclusions}

The main conclusion drawn from the considerations and experimental data discussed here is that 18 carat white jewellery gold alloys as a whole can with advantage be considered in relation to the ternary gold-silver-palladium system. On this basis, their mechanical properties can be directly correlated with their total copper + nickel + zinc content, irrespective of the precise composition of the gold-silverpalladium matrix, and alloys devoid of either nickel or palladium can be viewed as extreme cases only.

While the presence of zinc is an essential requirement for any form of age hardening to take place in these alloys, the nature of the mechanisms leading to this hardening, as well as its extent, are affected by the nickel concentration. The solid state reactions responsible for age hardening are slow and heat treatment lasting several tens of hours may be required to reach equilibrium.

The best compromise between mechanical properties and colour is achieved in 18 carat alloys con- sisting of six components, namely gold, silver, palladium, copper, nickel and zinc. The colour diagram proposed here enables the prediction of the colour of new formulations incorporating these six components, in spite of their complexity.

\section{References}

1 A. S. MeDonald and G. H. Sistare, Gold Bull., 1978, 11, (3), 66-73 and (4), 128-131

2 E. Raub and A. Engel, Metallforsch, 1947, 2, 11-16 and $147-158$

3 W. S. Rapson and 'T. Groenewald, 'Gold Usage', Academic Press, L.ondon, 1978, pp. 41-49

4 G. P. O'Connor, Gold Bull., 1978, 11, (2), 35-39

5 T. Groenewald, R. W. Quail and E. Krugel, Chamber of Mines of Sourh Africa, Research Organisation, private communication, 1977

$6 \mathrm{M}$. Hansen and $\mathrm{K}$. Anderko, 'Constitution of Binary Mlloys', 2nd edition, McGraw-Hill Book Co., Inc., New York, 1958

7 J. Halner and R. Volterra in 'Metals Handbook', vol. 1, 8th edition, American Society for Metals, 1961, p. 1195

8 Deutsche Industrie Normen, DIN 50101, 1961; after International Organization for Standardization, ISO-Recommendation 149-1960

9 J.-J. Labarge, D. Tréheux and P. Guiraldenq, Gold Bull., $1979,12,(2), 46-52$

\title{
New Facility for Refining of Precious Metals
}

Johnson Matthey Chemicals Limited, international refiners of precious metals, have announced the introduction of substantial improvements and extensions to the company's precious metals refining facilities with the opening of a new installation at Brimsdown, near Enfield, England. The new plant is complementary to the company's Royston facility where precious metals are further refined to purities of up to 99.99 per cent.

The input materials cover the full range of precious metal-bearing concentrates, residues, bullion, scrap and waste material from industrial consumers in the jewellery, photographic, electronics, chemical and decorative industries.
The precious metal refining business is unique in that the customer often has no accurate knowledge of the value of the material he delivers for refining. This places a heavy responsibility on the refiner, especially as the material varies considerably in form, homogeneity and content of valuable metals. Particular attention has therefore been given at Brinssdown to facilities which enable material to be converted to a state from which truly representative samples can be taken for precious metals assays. The most modern equipment has also been installed for such assays.

We hope to be able to present an account of the procedures and refining processes used in precious metal recovery in a future issue of Gold Bulletin.

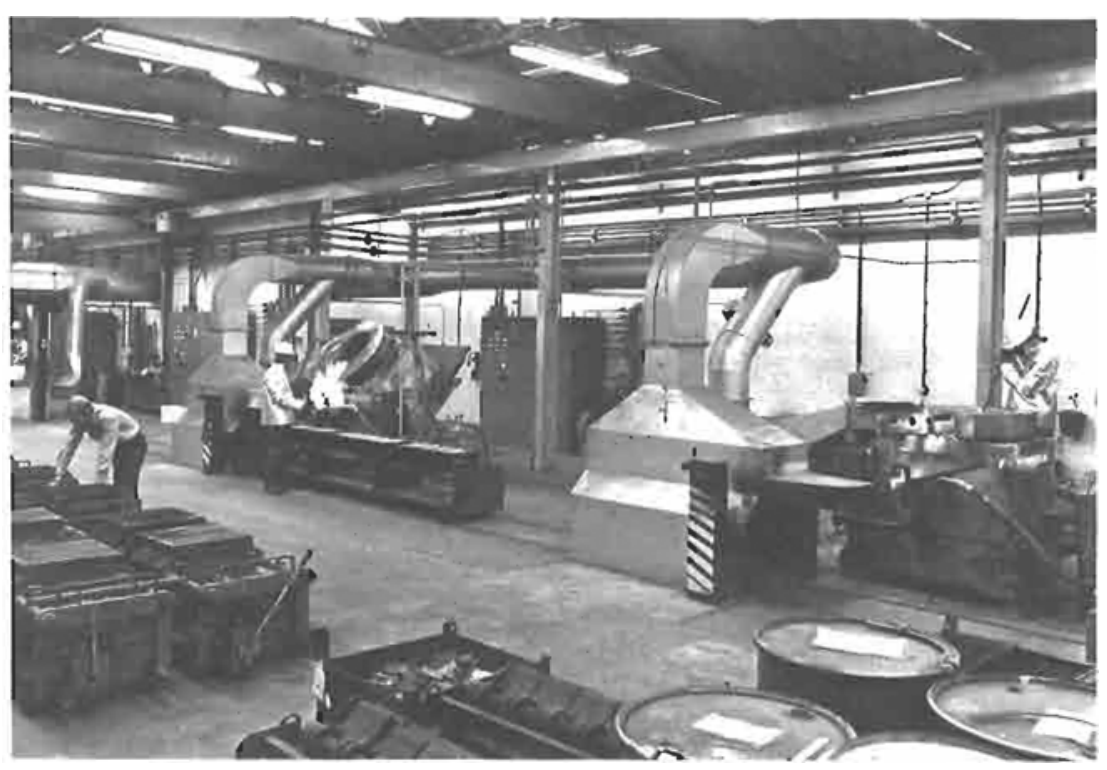

Two of the nine electrical induction furnaces recently commissioned at Johnson Matthey Chenicals precious metals refinery at Brinsdown are visible in this partial view of the melting house 